\title{
Cytotechnologist-Attended On-Site Evaluation of Adequacy for Metastatic Disease Involving Bone and Soft Tissue
}

\author{
Matthew T. Olson ${ }^{a} \quad$ Anna Novak $^{\mathrm{a}}$ John Kirby ${ }^{\mathrm{a}}$ Hinna Shahid ${ }^{\mathrm{a}}$ \\ Thiraphon Boonyaarunnate ${ }^{\mathrm{a}, \mathrm{c}}$ Syed Z. Ali ${ }^{\mathrm{a}, \mathrm{b}}$ \\ Departments of a Pathology and ${ }^{b}$ Radiology, The Johns Hopkins School of Medicine, Baltimore, Md., USA; \\ 'Department of Pathology, Faculty of Medicine, Siriraj Hospital, Mahidol University, Bangkok, Thailand
}

\section{Key Words}

Fine needle aspiration - On-site evaluation of adequacy .

Soft tissue - Metastatic carcinoma - Lymphoma .

Cytotechnologist

\begin{abstract}
Introduction: Image-guided fine needle aspiration (FNA) of the musculoskeletal system is expensive to perform and repeat, so on-site evaluation of adequacy (OSEA) is increasingly used to ensure an optimal sample. Metastatic disease to the musculoskeletal system is not uncommon and often requires OSEA when sampled. At large academic centers, cytotechnologists have filled the increased demand for OSEA. However, the performance of cytotechnologists has not been compared with that of cytopathologists for OSEA in FNA of metastatic disease involving bone and soft tissue. Methods: We retrospectively analyzed 10 years of data in which both cytotechnologists and cytopathologists performed OSEA for 1,995 FNAs of bone and soft tissue sites in which metastatic malignancy was suspected or found. We calculated adequacy and accuracy statistics in conjunction with other variables including imaging modality, biopsy site, accompanying core biopsy, tissue type, final diagnosis, and number of smears. Results: A total of 1,995 aspirates of met-
\end{abstract}

astatic disease carcinoma, melanoma or lymphoma to bone or soft tissue had OSEA performed by cytotechnologists $(681,33.7 \%)$ or cytopathologists $(1,314,66.3 \%)$. The adequacy downgrade rate was statistically equivalent (4.1 vs. $3.6 \%$; $\mathrm{p}=0.64)$. Conclusion: Cytotechnologists and cytopathologists perform with reasonable equivalence at OSEA of aspirates from metastatic carcinoma, melanoma or lymphoma involving bone or soft tissue.

(c) 2013 S. Karger AG, Basel

Fine needle aspiration (FNA) is an important component in the diagnostic process for metastases, especially since the resection of metastatic disease is commonly not clinically indicated. Aspirated material is amenable to ancillary testing including flow cytometry, immunohistochemistry and molecular testing, so the FNA procedure can provide sufficient and actionable information for the next step in patient management. As tumors involving bone and soft tissue can be deep-seated, aspirating them often requires imaging guidance [1]. While the use of imaging guidance clearly increases the safety of the biopsy procedure, it adds time and cost $[2,3]$. Thus, clinical practices that increase the diagnostic yield and decrease the need for repeat FNA or invasive procedures are necessary

\section{KARGER}

E-Mail karger@karger.com www.karger.com/acy
(C) 2013 S. Karger AG, Basel

0001-5547/13/0576-0550\$38.00/0
Correspondence to: Dr. Syed Z. Ali

Department of Pathology, The Johns Hopkins Hospital, Pathology 406 600 N. Wolfe St.

Baltimore, MD 21287 (USA)

E-Mail sali@jhmi.edu 
Table 1. Definition of adequacy and accuracy for this review

\begin{tabular}{|c|c|c|c|}
\hline \multirow[t]{2}{*}{ On-site adequacy } & \multicolumn{3}{|l|}{ Sign-out diagnosis } \\
\hline & benign or malignant & indeterminate & inadequate \\
\hline Adequate & agreement & downgrade & downgrade \\
\hline Less than optimal & upgrade & agreement & agreement \\
\hline Inadequate & upgrade & upgrade & agreement \\
\hline
\end{tabular}

If the adequacy at sign-out is in agreement or upgraded from the on-site adequacy (white or light grey cells), this is considered 'accurate'. If the adequacy at sign-out is downgraded from an 'adequate' OSEA determination (dark grey cells), this is considered 'inaccurate'. There is no downgrade from less than optimal.

for patient safety and cost effectiveness. Several investigators have attempted and published various strategies to increase the diagnostic yield of the FNA procedure. Several measures have been tested including routine performance of numerous passes $[4,5]$, direct smear gross examination [6-8] and on-site evaluation of adequacy (OSEA) [9]. Given the time constraints on practicing cytopathologists, divesting them from other clinical functions in order to perform OSEA presents a significant logistical challenge. Alternatives have been proposed including non-cytologist-performed OSEA $[10,11]$ and cytotechnologist-performed OSEA [12-15]. Our own experience has shown that cytotechnologists perform similarly to cytopathologists in OSEA of thyroid [14] and endoscopic ultrasound (US)-guided pancreas FNA [15]. However, such a study focusing on metastatic disease involving bone and soft tissue tumors has not been performed.

\section{Methods}

\section{Patients and Specimens}

All cases of FNA with OSEA were retrieved from the computerized record system of the Johns Hopkins Hospital for the dates between April 2003 and March 2012. Cases were performed under guidance using US $(n=1,393)$ or computerized tomography (CT, $\mathrm{n}=602$ ). During the study period, OSEA at CT-guided procedures changed from being cytopathologist attended to cytotechnologist attended. By contrast, OSEA at US-guided procedures were routinely performed by cytopathologists and only occasionally by cytotechnologists when a cytopathologist was not available. As only very few cases were performed with magnetic resonance imaging $(n=1)$, fluoroscopy $(n=1)$, endoscopic bronchoscopic US $(n=8)$, and without guidance $(\mathrm{n}=4)$, these cases were excluded. The 136 cases of endoscopic US-guided FNA were also excluded because only one of these was performed by a cytopathologist. Cases without OSEA were excluded. Additionally, the case set was restricted to patients with metastatic carcinoma $(\mathrm{n}=509)$, lymphoma $(\mathrm{n}=$
216), melanoma $(n=60)$, and neuroendocrine neoplasms $(n=20)$. Cases from these patients were included if the final result was positive for malignancy or benign, atypical, or inadequate, as long as a suspicion for these diagnoses prompted the procedure. Cases performed for primary bone or soft tissue neoplasms or which eventually resulted in a resection with one of those diagnoses involved a distinct set of diagnostic issues and will be reported separately.

\section{Cytopathology}

Smears were prepared in duplicate and included at least one air-dried slide for Diff-Quik staining and OSEA and an alcoholfixed slide for Papanicolaou staining as the material allowed. OSEA was performed by 1 of 6 cytotechnologists or 1 of 14 board-certified cytopathologists. Each procedure was given an on-site adequacy evaluation of either 'adequate', 'less than optimal' or 'inadequate'. The 'adequate' on-site evaluation designated cases in which a definitive diagnosis could be made based on the material seen; 'inadequate' designated that no diagnosis could be made based on the material seen; and 'less than optimal' designated cases in which the diagnosis was predicted to be uncertain based on the material seen on site. Preliminary diagnostic impressions are not given at our institution in this context.

All the cytologic material was previewed by a cytotechnologist and signed out by a board-certified cytopathologist. If the OSEA was attended by a cytopathologist, then the same cytopathologist rendered the final diagnosis and adequacy evaluation. Adequacy agreement, upgrade and downgrade were defined according to table 1 . Given the fact that half the diagnostic material was unavailable to the cytologist at the time of the OSEA, accuracy was defined as either complete agreement or an upgrade of adequacy. Conversion from less than optimal to inadequate was also classified as agreement. Final diagnoses were assigned into 1 of 4 categories: benign, malignant, other, and unsatisfactory.

\section{Data Analysis and Statistics}

The retrieved data were queried with a custom Perl script for the cytologist performing OSEA, the OSEA verdict, the final adequacy, and the final diagnosis. Summary diagnosis, sign-out adequacy and body site were manually verified using a Filemaker Pro 12 (Santa Clara, Calif., USA) graphical user interface. After manual verification, the data were imported into R (http://cran. r-project.org) for all statistical analyses. Categorical variables such 
Fig. 1. Adequacy and accuracy rates for the cytotechnologists (CT) and cytopathologists (MD) who performed $>25$ OSEA during the study period (figures given in parentheses are numbers of OSEA). The error bars are $95 \%$ confidence intervals. The asterisks indicate that the confidence interval crosses $100 \%$.

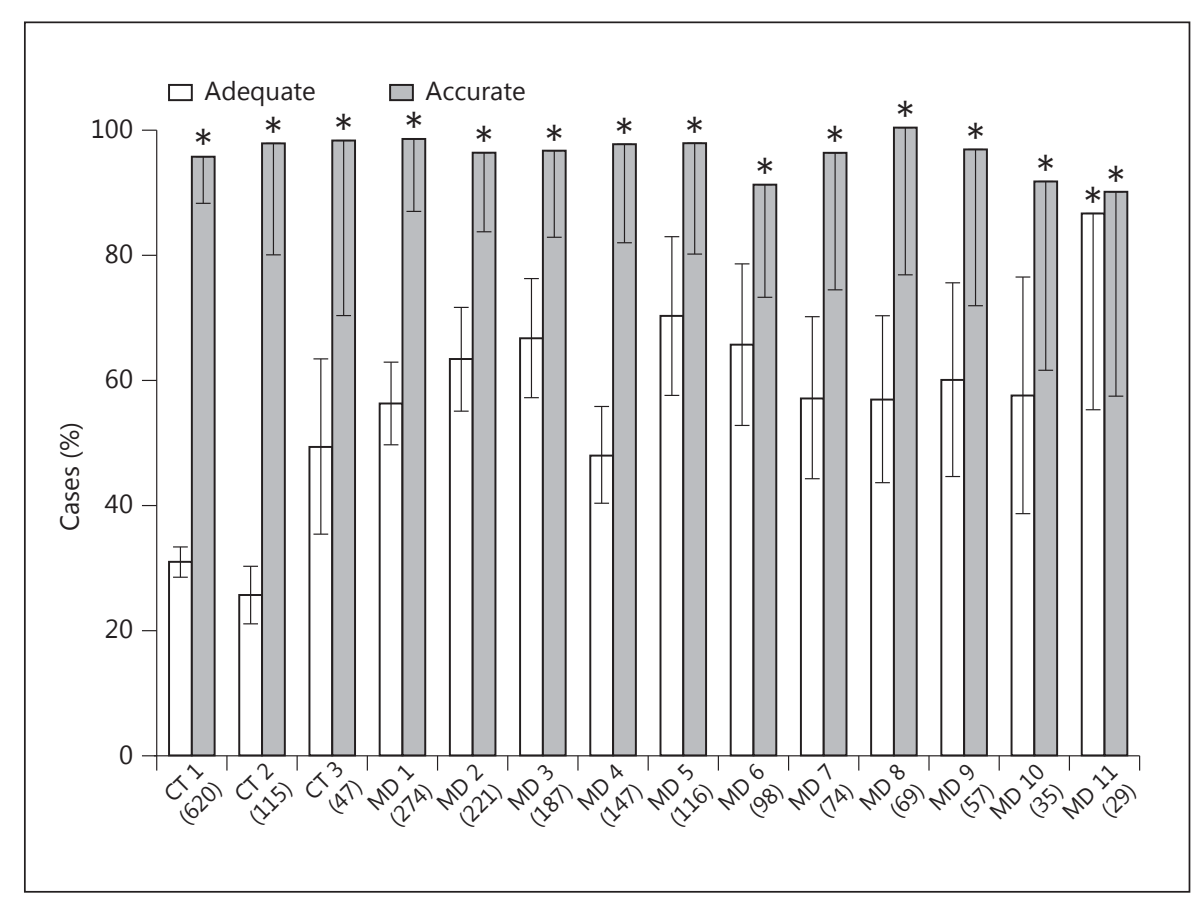

as OSEA provider type, adequacy and accuracy were converted into integers for ANOVA [16]. The 95\% confidence intervals for the adequacy and accuracy counts for each provider were calculated, including the total number of cases performed by that provider. Age differences, differences in the year of the FNA procedure and differences in the number of smears for the patient groups were evaluated with the Student $t$ test [17]. The $\chi^{2}$ test with the Yates continuity correction [18] was used for comparisons involving gender, biopsy site, diagnostic category, accuracy, and adequacy. The Fisher exact test [19] was used for comparisons involving slices of the data with counts $<20$.

\section{Results}

A total of 1,995 aspirates of bone and soft tissue met the inclusion criteria. Of these, 681 (34.1\%) were attended by 1 of 6 cytotechnologists, and 1,314 (65.9\%) were attended by 1 of 14 board-certified cytopathologists. The overall adequacy was $53.0 \%$ on site $(1,015 / 1,995)$ and $69.0 \%(1,377 / 1,995)$ at sign-out. Aggregated statistics for adequacy agreements, upgrades and downgrades for cytopathologists and cytotechnologists are shown in table 2. There was a significantly higher likelihood for cytotechnologist-performed OSEA to undergo an adequacy upgrade than for those performed by cytopathologists ( 34.2 vs. $18.9 \%$; $\mathrm{p}<0.0000001)$. However, the rate of adequacy downgrade was statistically equivalent (4.1 vs. $3.6 \%$; $\mathrm{p}=$
Table 2. Accuracy of cytotechnologist- and cytopathologist-performed OSEA

\begin{tabular}{lcc}
\hline $\begin{array}{l}\text { OSEA } \\
\text { versus sign-out } \\
\text { adequacy }\end{array}$ & Cytotechnologist & Cytopathologist \\
\hline Downgraded & $28(4.1)$ & $47(3.6)$ \\
Accurate & $420(61.7)$ & $1,018(77.5)$ \\
Upgraded & $233(34.2)$ & $249(18.9)$ \\
\hline Total & 681 & 1,314 \\
\hline
\end{tabular}

Figures in parentheses are percentages.

$0.64)$ for cytopathologists and cytotechnologists. Figure 1 shows the distribution of adequacy rates for cytotechnologists and cytopathologists who performed at least 25 OSEA. As shown in that figure, there was a broad distribution of adequacy rates. When taken as a whole, the onsite adequacy rate for cases evaluated by cytotechnologists was significantly lower than that for cases evaluated by cytopathologists in this set of cases ( 32.1 vs. $60.5 \%$; $\mathrm{p}<0.0000001$ ); cytotechnologists were significantly more likely to use the less than optimal designation for this specimen type ( 47.5 vs. $17.7 \%$; $\mathrm{p}<0.0000001$ ). There was no difference in accuracy; all accuracy confidence inter- 
Table 3. Procedure characteristics for cytotechnologist- and cytopathologist-performed OSEA

\begin{tabular}{|c|c|c|c|}
\hline Variable & $\begin{array}{l}\text { Cytotech- } \\
\text { nologist }\end{array}$ & $\begin{array}{l}\text { Cytopa- } \\
\text { thologist }\end{array}$ & $\mathrm{p}$ \\
\hline Number of OSEA & $681(34)$ & $1,314(66)$ & \\
\hline Average year of OSEA & $2009 \pm 2.2$ & $2009 \pm 1.8$ & 0.13 \\
\hline \multicolumn{3}{|c|}{ Average patient age, } & $0.00004^{*}$ \\
\hline Gender ratio (F:M) & 1.06 & 0.96 & 0.25 \\
\hline Average smears/case & $5.6 \pm 2.7$ & $5.6 \pm 2.6$ & 0.79 \\
\hline \multicolumn{4}{|l|}{ Guidance } \\
\hline US & $159(23)$ & $1,234(94)$ & $<0.000001^{*}$ \\
\hline CT & $522(77)$ & $159(6)$ & \\
\hline \multicolumn{4}{|l|}{ Biopsy site } \\
\hline Head & $4(0.6)$ & $75(5.7)$ & $<0.000001^{*}$ \\
\hline Neck & $62(9.1)$ & $233(18)$ & \\
\hline Upper extremity & $89(13)$ & $134(10)$ & \\
\hline Thorax & $39(5.7)$ & $164(13)$ & \\
\hline Abdomen & $27(4.0)$ & $208(16)$ & \\
\hline Retroperitoneum & - & $86(6.5)$ & \\
\hline Spine & $54(8.0)$ & $50(7.9)$ & \\
\hline Pelvis & $179(26)$ & $206(16)$ & \\
\hline Lower extremity & $227(33)$ & $158(12)$ & \\
\hline \multicolumn{4}{|l|}{ Core biopsy } \\
\hline Yes & $341(50)$ & $593(45)$ & $0.04^{*}$ \\
\hline No & $340(50)$ & $721(55)$ & \\
\hline \multicolumn{4}{|l|}{ Tissue type } \\
\hline Bone & $420(62)$ & $76(6)$ & $<0.000001^{*}$ \\
\hline Soft tissue & $261(38)$ & $1,238(94)$ & \\
\hline
\end{tabular}

Figures in parentheses are percentages. ${ }^{*}$ Significant at $\mathrm{p}<0.05$.

vals crossed the unity regardless of the provider. The lower rate of on-site adequacy calls for cytotechnologists did not translate into the collection of more smears; cytotechnologist and cytopathologist cases had a median of 5 smears each (one-sided $\mathrm{p}=0.9$ ).

The differences between cases with OSEA attended by cytotechnologists and cytopathologists are outlined in table 3. The biopsies for each patient group were contemporaneous, and the gender composition was similar. The cytopathologist patient group was slightly but significantly older and more likely to have a biopsy guided by US. Cytotechnologist-performed OSEA, on the other hand, were more often guided by CT and were slightly more likely to have a core biopsy. There was also a significant difference in the distribution of body sites evaluated by the two provider groups; a larger portion of the cytotechnologist workload was spent on the pelvis and extremities compared to the cytopathologist workload, which was more uniformly distributed across the entire body.

Cytotechnologist-Attended OSEA for

Metastatic Disease
Table 4. Association of variables with adequacy rate

\begin{tabular}{|c|c|c|c|}
\hline Variable & $\begin{array}{l}\text { Cases, } \\
\mathrm{n}\end{array}$ & $\begin{array}{l}\text { Adequacy, } \\
\%\end{array}$ & $\mathrm{p}$ \\
\hline \multicolumn{4}{|l|}{ Guidance } \\
\hline US & $1,393(70)$ & 73.0 & $<0.0000001^{*}$ \\
\hline CT & $602(30)$ & 60.3 & \\
\hline \multicolumn{4}{|l|}{ Location } \\
\hline Head & $79(4)$ & 70.9 & $0.0000004^{*}$ \\
\hline Neck & $295(15)$ & 72.9 & \\
\hline Thorax & $203(10)$ & 76.4 & \\
\hline Abdomen & $235(12)$ & 79.1 & \\
\hline Retroperitoneum & $86(4)$ & 75.6 & \\
\hline Spine & $104(5)$ & 56.7 & \\
\hline Pelvis & $385(19)$ & 67.3 & \\
\hline Upper extremity & $223(11)$ & 63.2 & \\
\hline Lower extremity & $385(19)$ & 62.6 & \\
\hline \multicolumn{4}{|l|}{ Tissue type } \\
\hline Bone & $496(25)$ & 58.5 & 0.68 \\
\hline Soft tissue & $1,499(75)$ & 72.5 & \\
\hline \multicolumn{4}{|l|}{ OSEA provider } \\
\hline Cytotechnologist & $681(34)$ & 59.5 & 0.44 \\
\hline Cytopathologist & $1,314(66)$ & 74.0 & \\
\hline \multicolumn{4}{|l|}{ Core biopsy } \\
\hline Yes & $1,061(53)$ & 81.3 & $<0.0000001^{*}$ \\
\hline No & $934(47)$ & 58.2 & \\
\hline \multicolumn{4}{|l|}{ Adequacy at OSEA } \\
\hline Insufficient & $429(22)$ & 25.4 & $<0.0000001^{*}$ \\
\hline Less than optimal & $551(28)$ & 60.0 & \\
\hline Adequate & $1,015(50)$ & 92.6 & \\
\hline $\begin{array}{l}\text { Median number of } \\
\text { smears }\end{array}$ & $5[1-18]$ & - & 0.08 \\
\hline
\end{tabular}

Figures in parentheses are percentages; figures in brackets indicate the range. ${ }^{*}$ Statistically significant at $\mathrm{p}<0.05$.

We performed an ANOVA to consider the factors associated with adequacy and accuracy of OSEA. The results for the variables associated with adequacy are shown in table 4 . There was a direct correlation between the adequacy rendered on site and the final adequacy evaluation. The number of smears trended with adequacy, but this was not significant. The guidance method correlated significantly with adequacy; US-guided procedures were more likely to be adequate than CT-guided procedures. Interestingly, lesions in the bone were less likely to be adequate, but the difference to adequacy from lesions in the soft tissue was not significant. Body site also correlated with adequacy in this series; the least adequate sites were the spine and the extremities, while abdominal and retroperitoneal aspirates were most commonly adequate. While the on-site adequacy rates were lower for OSEA 
Table 5. Association of variables with accuracy rate

\begin{tabular}{|c|c|c|c|}
\hline Variable & Cases & $\begin{array}{l}\text { Adequacy } \\
\text { down- } \\
\text { graded, \% }\end{array}$ & $\mathrm{p}$ \\
\hline \multicolumn{4}{|l|}{ Guidance } \\
\hline US & $1,393(70)$ & 3.7 & 0.97 \\
\hline $\mathrm{CT}$ & $602(30)$ & 4.0 & \\
\hline \multicolumn{4}{|l|}{ Location } \\
\hline Head & $79(4)$ & 1.3 & $0.00001^{*}$ \\
\hline Neck & $295(15)$ & 3.1 & \\
\hline Thorax & $203(10)$ & 3.9 & \\
\hline Abdomen & $235(12)$ & 2.1 & \\
\hline Retroperitoneum & $86(4)$ & 4.7 & \\
\hline Spine & $104(5)$ & 1.0 & \\
\hline Pelvis & 385 (19) & 4.9 & \\
\hline Upper extremity & $223(11)$ & 5.8 & \\
\hline Lower extremity & 385 (19) & 3.9 & \\
\hline \multicolumn{4}{|l|}{ Tissue type } \\
\hline Bone & $496(25)$ & 5.2 & 0.34 \\
\hline Soft tissue & $1,499(75)$ & 3.3 & \\
\hline \multicolumn{4}{|l|}{ OSEA provider } \\
\hline Cytotechnologist & $681(34)$ & 4.1 & 0.40 \\
\hline Cytopathologist & $1,314(66)$ & 3.6 & \\
\hline \multicolumn{4}{|l|}{ Core biopsy } \\
\hline No & $1,061(53)$ & 4.1 & $<0.0000001^{*}$ \\
\hline Yes & $934(47)$ & 3.3 & \\
\hline \multicolumn{4}{|l|}{ Adequacy at OSEA } \\
\hline Insufficient & $429(22)$ & - & $<0.0000001^{*}$ \\
\hline Less than optimal & $551(28)$ & - & \\
\hline Adequate & $1,015(50)$ & 7.4 & \\
\hline $\begin{array}{l}\text { Median number of } \\
\text { smears }\end{array}$ & $5[1-18]$ & - & $0.01^{*}$ \\
\hline
\end{tabular}

Figures in parentheses are percentages; figures in brackets indicate the range. ${ }^{*}$ Statistically significant at $\mathrm{p}<0.05$.

diagnosed by cytotechnologists, the sign-out adequacy rates in table 4 did not appear to be correlated with the OSEA provider type.

The results for the variables associated with the accuracy of OSEA are shown in table 5. There was no relationship between accuracy and the type of OSEA provider, imaging modality, or the sampling of bone or soft tissue. On the other hand, specific body sites did show a significant accuracy difference; OSEA of the extremities and pelvis were significantly less accurate than those of the other sites. Additionally, the availability of a core biopsy factored significantly into the ultimate accuracy of the OSEA. Cases without a core biopsy were slightly but significantly more likely to have an adequacy downgrade. Only cases that were called adequate on site could undergo an adequacy downgrade in the algorithm shown in
Table 6. Lymphoma specimens collected for flow cytometry divided by OSEA provider

\begin{tabular}{ccc}
\hline & $\begin{array}{l}\text { Flow cytometry } \\
\text { performed }\end{array}$ & $\begin{array}{l}\text { Flow cytometry } \\
\text { not performed }\end{array}$ \\
\hline Lymphoma $(\mathrm{n}=218)$ & 132 & 86 \\
Cytopathologist OSEA & 105 & 68 \\
Cytotechnologist OSEA & 27 & 18 \\
Other malignancy ( $\mathrm{n}=587)$ & 6 & 581 \\
Cytopathologist OSEA & 4 & 470 \\
Cytotechnologist OSEA & 2 & 111 \\
\hline
\end{tabular}

table 1 , so clearly on-site adequacy was significantly related with the rate of adequacy downgrade. Finally, there was a significant association between the number of direct smears and adequacy; cases with more direct smears were less likely to have the adequacy downgraded. For example, cases with two direct smears had an adequacy downgrade rate of $8.0 \%$ while cases with eight direct smears had an adequacy downgrade rate of 3.3\%.

To evaluate roles such as the triage of the specimen for the purposes of suggesting appropriate specimen storage, cases of lymphoma were examined separately to determine how many specimens were sent for flow cytometry and if there was a significant difference for the cases with cytotechnologist-performed OSEA. The results are shown in table 6 . Of the 216 cases of lymphoma, 172 had cytopathologist-performed OSEA and 44 had cytotechnologist-performed OSEA. There was no significant difference in the proportion of these cases that had properly preserved material for flow cytometry (27/45 vs. 105/173; $\mathrm{p}=0.99$ ). Conversely, among the 589 definitively malignant non-lymphoma cases, cytotechnologist-performed OSEA was not associated with excessive procurement for flow cytometry $(4 / 474$ vs. $2 / 113 ; p=0.19)$. The 6 nonlymphoma cases that were analyzed with flow cytometry were small blue cell tumors: melanoma $(\mathrm{n}=1)$ and small cell carcinoma $(\mathrm{n}=5)$.

\section{Discussion}

The results presented here demonstrate an acceptable interchangeability of cytotechnologists and cytopathologists for OSEA of aspirates from metastatic disease involving bone and soft tissue. These results are commensurate with our previous studies on this topic $[14,15]$, but this study differs from the prior ones in that there is no 
penalty for an adequacy change from less than optimal to inadequate. This is because indeterminate diagnoses for the thyroid and pancreas often have actionable implications while aspirates of metastatic carcinoma often require a definitive diagnosis for the next step in management. Thus, the change from less than optimal to inadequate is expected to have little effect since both would require additional investigation or tissue studies in order to establish a clinical plan. As in other studies, adequacy upgrades are not penalized since half of the material obtained from the FNA procedure is alcohol fixed, so not available for review at the time of biopsy. Thus, adequacy upgrades are expected and should be common.

In this study, adequacy upgrades were more common among cytotechnologists than among cytopathologists, and this is likely a reflection of the fact that cytopathologists render their own sign-out diagnosis while cytotechnologists do not. An alternative explanation is that cytotechnologists may practice OSEA with more caution than cytopathologists due to the fact that they are not ultimately responsible for the final diagnosis. The contribution of these factors cannot be easily distinguished. More importantly, this tendency to underestimate adequacy clearly does not result in a difference in FNA passes, so this difference between cytotechnologist and cytopathologist adequacy evaluations is probably of minimal clinical significance.

The retrospective nature of this study is a significant limitation in that there is little parity between the patients who had cytotechnologist- and cytopathologist-performed OSEA. This study shows that there are significant demographic and procedural differences between the two patient groups. For example, cytotechnologist-performed
OSEA in this study are heavily weighted towards bone FNA guided by CT, and there are an inadequate number of cytopathologist-performed OSEA for a direct comparison of this procedure subset. This limitation is a reflection of our practice environment; CT-guided procedures usually take substantially more time than US-guided procedures, so those are more readily assigned to cytotechnologists. This is probably a reasonable explanation for the higher rate of core biopsies among cytotechnologistperformed OSEA cases and may also partially contribute to the higher rate of post-facto adequacy upgrade.

This study comprises additional support to the notion that cytotechnologists are suited for the role of OSEA. However, laboratories in the United States may not bill for cytotechnologist-performed OSEA services. Even though OSEA clearly decreases the costs involved in diagnostic tissue procurement [20-23], and cytotechnologist-performed OSEA could be implemented at a lower cost than cytopathologist-performed OSEA, widespread adoption of cytotechnologist-performed OSEA has not occurred. This is probably the case because in order for institutions to engage in un-reimbursed cytotechnologist-performed OSEA, they have to evaluate the cost-effectiveness on a macro-scale institutional level [12]. Large academic centers, for example, have been quick to give cytotechnologists these duties [13-15]. While a randomized clinical trial has yet to be performed and published, the data shown here and elsewhere [13-15] have shown sufficient performance of cytotechnologists for OSEA and form a sufficient basis for pursuing this level of evidence as part of the evidence needed to request the addition to the current medical services fee schedule.

\section{References}

-1 Kwan SW, Bhargavan M, Kerlan RK, Sunshine JH: Effect of advanced imaging technology on how biopsies are done and who does them. Radiology 2010;256:751-758.

$\checkmark 2$ Maya ID, Maddela P, Barker J, Allon M: Percutaneous renal biopsy: comparison of blind and real-time ultrasound-guided technique. Semin Dial 2007;20:355-358.

-3 Farrell RJ, Smiddy PF, Pilkington RM, Tobin AA, Mooney EE, Temperley IJ, et al: Guided versus blind liver biopsy for chronic hepatitis C: clinical benefits and costs. J Hepatol 1999; 30:580-587.

4 Rossi ED, Morassi F, Santeusanio G, Zannoni GF, Fadda G: Thyroid fine needle aspiration cytology processed by ThinPrep: an addition- al slide decreased the number of inadequate results. Cytopathology 2010;21:97-102.

$\checkmark 5$ Eedes CR, Wang HH: Cost-effectiveness of immediate specimen adequacy assessment of thyroid fine-needle aspirations. Am J Clin Pathol 2004;121:64-69.

6 Mayall F, Cormack A, Slater S, McAnulty K: The utility of assessing the gross appearances of FNA specimens. Cytopathology 2010;21: 395-397.

7 Prayaga AK, Vijaya K: Role of unstained smears in determining sample adequacy. Acta Cytol 2004;48:321-324.

-8 Nguyen YP, Maple JT, Zhang Q, Ylagan LR, Zhai J, Kohlmeier C, et al: Reliability of gross visual assessment of specimen adequacy dur- ing EUS-guided FNA of pancreatic masses. Gastrointest Endosc 2009;69:1264-1270.

$>9$ Nasuti JF, Gupta PK, Baloch ZW: Diagnostic value and cost-effectiveness of on-site evaluation of fine-needle aspiration specimens: review of 5,688 cases. Diagn Cytopathol 2002; 27:1-4.

10 Savoy AD, Raimondo M, Woodward TA, Noh K, Pungpapong S, Jones AD, et al: Can endosonographers evaluate on-site cytologic adequacy? A comparison with cytotechnologists. Gastrointest Endosc 2007;65:953-957.

11 Renshaw AA: 88172 is more than counting cells: ensuring the quality of immediate assessment of fine-needle aspiration material. Am J Clin Pathol 2012;138:27-28.
Cytotechnologist-Attended OSEA for Metastatic Disease
Acta Cytologica 2013;57:550-556 DOI: $10.1159 / 000354079$ 
12 Wotruba AL, Stewart J, Scheberl T, Selvaggi SM: Added value, decreased cost: the evolving role of the cytotechnologist for preliminary screening and triage of thyroid aspirates. $\mathrm{Di}$ agn Cytopathol 2011;39:896-899.

13 Burlingame OO, Kessé KO, Silverman SG, Cibas ES: On-site adequacy evaluations performed by cytotechnologists: correlation with final interpretations of 5241 image-guided fine-needle aspiration biopsies. Cancer Cytopathol 2012;120:177-184.

14 Olson MT, Tatsas AD, Ali SZ: Cytotechnologist-attended on-site adequacy evaluation of thyroid fine needle aspiration: comparison with cytopathologists and correlation with the final interpretation. Am J Clin Pathol 2011;138:90-95.
15 Olson MT, Ali SZ: Cytotechnologist on-site evaluation of pancreas fine needle aspiration adequacy: comparison with cytopathologists and correlation with the final interpretation. Acta Cytol 2012;56:340-346.

16 Holm S: A simple sequentially rejective multiple test procedure. Scand J Stat 1979;6:6570.

17 Student: The probable error of a mean. Biometrika 1908;6:1-25.

18 Hope ACA: A simplified Monte Carlo significance test procedure. J R Statist Soc B 1968; 582-598.

19 Fisher RA: The logic of inductive inference. J R Statist Soc 1935;98:39-82.

20 Alsharif M, Carlo-Demovich J, Massey C, Madory JE, Lewin D, Medina A-M, et al: Telecytopathology for immediate evaluation of fine-needle aspiration specimens. Cancer Cytopathol 2010;118:119-126.
21 Klapman JB, Logrono R, Dye CE, Waxman I: Clinical impact of on-site cytopathology interpretation on endoscopic ultrasound-guided fine needle aspiration. Am J Gastroenterol 2003;98:1289-1294.

22 Afify AM, al-Khafaji BM, Kim B, Scheiman JM: Endoscopic ultrasound-guided fine needle aspiration of the pancreas. Diagnostic utility and accuracy. Acta Cytol 2003;47:341348.

23 Erickson RA, Sayage-Rabie L, Beissner RS: Factors predicting the number of EUS-guided fine-needle passes for diagnosis of pancreatic malignancies. Gastrointest Endosc 2000;51: 184-190. 